\title{
Inhibition of Metallic Corrosion Using Ficus Extract
}

\author{
A.Y. El-Etre," Z. El-Tantawy \\ Chemistry Department, Faculty of Science, Benha University, Benha, Egypt
}

Received 30 June 2005; accepted in revised form 5 April 2006

\begin{abstract}
The inhibitive action of the extract of Ficus nitida leaves toward general and pitting corrosion of $\mathrm{C}$-steel, nickel and zinc in different aqueous media was investigated. Weight loss measurements, potentiostatic and potentiodynamic polarization techniques were used in this study. It was found that the presence of ficus extract in the corrosive media (acidic, neutral or alkaline) decreases the corrosion rates of the three tested metals. The inhibition efficiency increases as the extract concentration is increased. The inhibition efficiency depends on the type of corroded metal and on the corrosive solution. It was also found that the presence of ficus extract in the chloride containing solution shifts the pitting potentials of the tested metals toward the noble direction. The inhibitive action of ficus extract is discussed in view of adsorption of its components, the poly aromatic compounds, friedelin, epifriedelanol and nitidol, on the metal surface. It was found that such adsorption follows Langmuir adsorption isotherm. The calculated values of the free energy of adsorption indicated that the adsorption process is spontaneous.
\end{abstract}

Keywords: C-steel, nickel, zinc, corrosion inhibition, natural products, ficus.

\section{Introduction}

C-steel is frequently used in many industrial applications. Nickel and zinc are used either by themselves or as coating for other metals for their corrosion prevention. The inhibition of corrosion of these metals in different aqueous media is very important from the economic point of view. Many researches were conducted to find out suitable corrosion inhibitors for them [1-8]. A large number of organic and inorganic compounds give promising results in this respect. However, most of these compounds are very dangerous to human and environment. Recently, many works were devoted to study the effects of some naturally occurring substances on the corrosion of different metals in different corrosive media [9-16].

\footnotetext{
${ }^{*}$ Corresponding author. E-mail address: aliyousry@hotmail.com
} 
Ficus nitida is a plant that belongs to Moraceae family. It is a widely cultivated tree throughout the world. It is one of the most common street trees in warm climates around the world due to ability to grow in inhospitable places with little requirements. Every year, very large quantities of green ficus leaves are cut off during the shaping process. The extract of these leaves, which contains many chemical compounds, may be utilized as corrosion inhibitor. The aim of the present work is to study the effect of the leaves extract of Ficus nitida on the corrosion of $\mathrm{C}$-steel, nickel and zinc, in acidic, neutral and alkaline solutions.

\section{Experimental}

Sheets of C-steel (L-52), pure nickel and pure zinc, each with apparent surface area of $12 \mathrm{~cm}^{2}(5 \times 1 \times 0.2 \mathrm{~cm})$, were used in the measurements of corrosion rate by weight loss experiments. The corrosion rate was calculated on the basis of the apparent surface area. The initial average weights of the used coupons were $7.93215,8.84572$ and 7.13524 grams for C-steel, nickel and zinc, respectively. The immersion time extends to four days, at $25 \pm 1{ }^{\circ} \mathrm{C}$. The results of the weight loss experiments are the mean of three runs, each with a fresh sheet and fresh electrolyte. The inhibition efficiency calculations were based on the weight loss measurements at the end of the whole exposure period. The percent of inhibition efficiency was calculated using the following equation:

$$
\mathrm{IE}=\left[\left(\mathrm{CR}_{\mathrm{f}}-\mathrm{CR}_{\mathrm{i}}\right) / \mathrm{CR}_{\mathrm{f}}\right] \times 100
$$

where $\mathrm{CR}_{\mathrm{f}}$ and $\mathrm{CR}_{\mathrm{i}}$ are the corrosion rates of the metal coupons, expressed by milligrams per square decimeter per day (mdd), in the absence and present of ficus extract, respectively.

For potentiostatic experiments, a cylindrical rod of every tested metal or alloy was embedded in araldite such as the exposed surface area is $1.0 \mathrm{~cm}^{2}$, and used as working electrode. The electrodes were polished with different grades of emery papers, degreased with acetone and rinsed by distilled water before immersed in the test solution. Potentiostatic polarization experiments were carried out using EG\&G model 173 Potentiostat / Galvanostat. A threecompartment cell, with a saturated calomel reference electrode (SCE) and a platinum foil auxiliary electrode, was used. The inhibition efficiency was calculated using the following equation:

$$
\mathrm{IE}=\left[\left(\mathrm{I}-\mathrm{I}_{\mathrm{i}}\right) / \mathrm{I}\right] \times 100
$$

where $I$ and $I_{i}$ are the corrosion rates in the free and inhibited solutions, respectively.

Potentiodynamic polarization experiments were carried out to define the pitting potentials for the tested electrodes. The same electrolytic cell and same potentiostat were also used. The potential applied on the working electrode was swept at scanning rate of $1.0 \mathrm{mV} / \mathrm{sec}$.

All chemicals used for preparing the test solutions were of analytical grade and the experiments were carried out at room temperature, $25 \pm 1{ }^{\circ} \mathrm{C}$.

The green leaves of Ficus nitida were collected and washed thoroughly by distilled water and dried in closed stove. Forty grams of finally divided dry 
leaves were covered by distilled water and left in the stove at $50{ }^{\circ} \mathrm{C}$ for $4 \mathrm{hrs}$. The mixture is then filtered and the filtrate was put in a petri dish and left in the stove at $30{ }^{\circ} \mathrm{C}$ for three days. The residual solid was collected and used directly in the experiments. It was found that every $10 \mathrm{~g}$ of the fresh leaves give about $1.1017 \mathrm{~g}$ of residual material as water soluble sludge.

\section{Results}

Table 1 contains the inhibition efficiencies of different concentrations of ficus extract toward corrosion of $\mathrm{C}$-steel, nickel and zinc in $0.1 \mathrm{M}$ of $\mathrm{HCl}, \mathrm{NaCl}$ and $\mathrm{NaOH}$ solutions, as obtained from weight loss experiments. Inspection of Table 1 reveals that the ficus extract acts as good corrosion inhibitor at many experimental conditions. Generally, the inhibition efficiency increases as the extract concentration is increased. The extract shows the highest efficiencies in the alkaline medium. On the other hand, the lowest inhibition efficiencies are established in the acidic medium.

Table 1. Corrosion rates (CR), mdd, and inhibition efficiencies for the tested metals as revealed from weight loss measurements.

\begin{tabular}{|c|c|c|c|c|c|c|c|}
\hline \multirow[t]{2}{*}{ Metal } & \multirow{2}{*}{$\begin{array}{l}\text { Inhibitor } \\
\text { conc., } \\
\text { ppm }\end{array}$} & \multicolumn{2}{|c|}{$\mathrm{HCl}(p H=1.2)$} & \multicolumn{2}{|c|}{$\mathrm{NaCl}(p H=7.0)$} & \multicolumn{2}{|c|}{$\mathrm{NaOH}(\mathrm{pH}=13)$} \\
\hline & & $C R$ & $I E$ & $C R$ & $I E$ & $C R$ & $I E$ \\
\hline \multirow{5}{*}{ 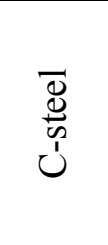 } & 0.00 & 49.65 & --- & 2.89 & --- & 4.43 & --- \\
\hline & 200 & 25.27 & 49 & 1.79 & 38 & 2.83 & 36 \\
\hline & 400 & 19.36 & 61 & 0.92 & 68 & 1.68 & 62 \\
\hline & 600 & 14.89 & 67 & 0.81 & 72 & 1.06 & 76 \\
\hline & 800 & 7.94 & 84 & 0.40 & 86 & 0.57 & 87 \\
\hline \multirow{5}{*}{ 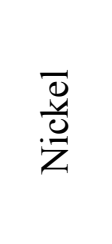 } & 0.00 & 19.29 & --- & 0.79 & --- & 7.37 & --- \\
\hline & 200 & 8.48 & 56 & 0.32 & 59 & 1.03 & 86 \\
\hline & 400 & 5.98 & 69 & 0.19 & 76 & 0.59 & 92 \\
\hline & 600 & 5.41 & 72 & 0.12 & 85 & 0.29 & 96 \\
\hline & 800 & 3.85 & 80 & 0.09 & 88 & 0.22 & 97 \\
\hline \multirow{5}{*}{$\stackrel{\circlearrowright}{N}$} & 0.00 & 158.52 & --- & 4.95 & --- & 53.89 & --- \\
\hline & 200 & 109.37 & 31 & 2.67 & 46 & 7.54 & 86 \\
\hline & 400 & 93.52 & 41 & 2.17 & 63 & 5.92 & 89 \\
\hline & 600 & 74.50 & 53 & 1.43 & 71 & 5.38 & 91 \\
\hline & 800 & 38.04 & 76 & 0.53 & 82 & 2.15 & 96 \\
\hline
\end{tabular}

Fig. 1 represents the anodic and cathodic polarization curves of $\mathrm{C}$-steel in $0.1 \mathrm{M}$ $\mathrm{HCl}$ solutions devoid of and containing different concentrations of ficus extract. Similar curves were also obtained in neutral and alkaline solutions as well as for nickel and zinc in all tested solutions. The other curves are not shown here because all of them have the same general feature. Inspection of Fig. 1 reveals that both anodic and cathodic potentials increase slightly at the low values of applied current density. At this stage, both cathodic and anodic reactions are established. This region of the polarization curve is known as the pre-Tafel 
region. As the applied anodic or cathodic current is increased further, one of the two reactions becomes predominant and the variation of potential becomes higher and thus the Tafel region is obtained. Tafel line must be straight for at least one decade of applied current density.

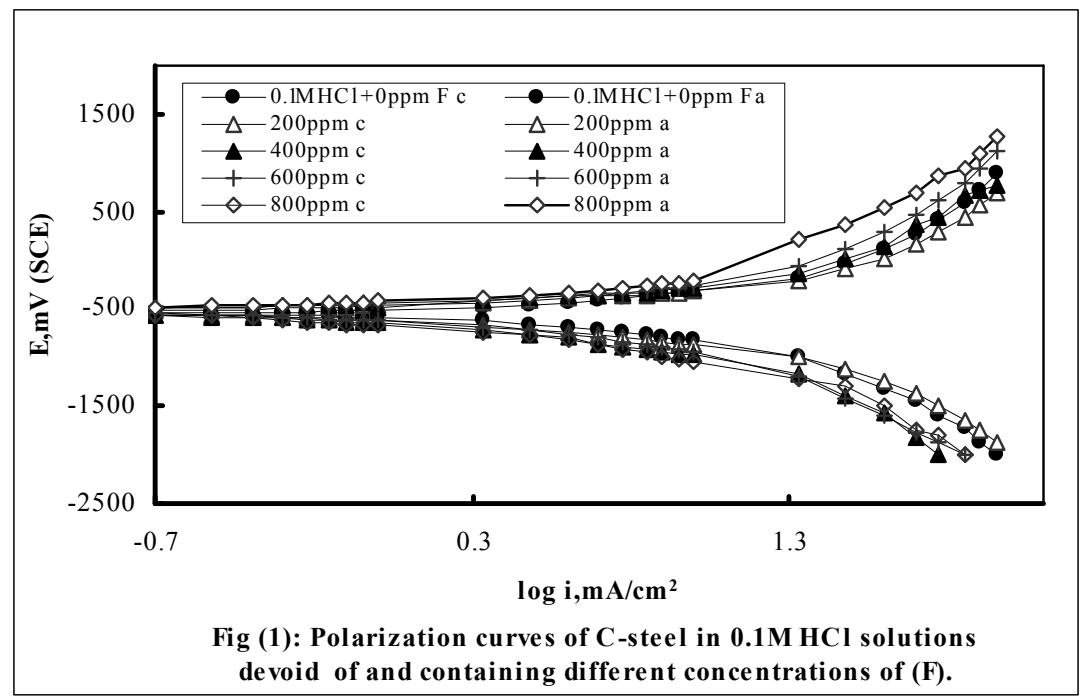

Table 2. Electrochemical parameters of C-steel corrosion in different media.

\begin{tabular}{|c|c|c|c|c|c|}
\hline Medium & $\begin{array}{c}\boldsymbol{\beta}_{\mathbf{a}} \\
\mathrm{mV} / \mathrm{decade}\end{array}$ & $\begin{array}{c}-\beta_{\mathbf{c}} \\
\mathrm{mV} / \mathrm{decade}\end{array}$ & $\begin{array}{c}-\mathbf{E}_{\text {corr }} \\
\mathrm{mV}\end{array}$ & $\begin{array}{c}\mathbf{i}_{\text {corr }} \\
\mathrm{mA} / \mathrm{cm}^{2}\end{array}$ & IE\% \\
\hline$\frac{\mathbf{0 . 1} \mathbf{M ~} \mathbf{H C l}+}{1-0 \quad \operatorname{ppm}(\mathrm{F})}$ & 360 & 380 & 565 & 1.9952 & \\
\hline $2-200 “$ & 200 & 340 & 520 & 0.8912 & 55.33 \\
\hline $3-400$ “ & 200 & 400 & 515 & 0.7943 & 67.14 \\
\hline $4-600$ “ & 240 & 400 & 515 & 0.6556 & 60.19 \\
\hline $5-800$ “ & 200 & 380 & 518 & 0.5412 & 72.87 \\
\hline$\frac{\mathbf{3 . 5 \%} \mathbf{N a C l}+}{1-0 \quad p p m(\mathrm{~F})}$ & 180 & 490 & 578 & 0.1166 & - \\
\hline $2-200$ “ & 160 & 485 & 576 & 0.0613 & 41.59 \\
\hline $3-400$ & 150 & 440 & 562 & 0.0541 & 53.58 \\
\hline $4-600 “$ & 125 & 420 & 550 & 0.0341 & 70.71 \\
\hline $5-800 “$ & 190 & 400 & 548 & 0.0207 & 82.22 \\
\hline$\frac{\mathbf{0 . 1} \mathbf{M ~ N a O H}+}{1-0 \quad \operatorname{ppm}(\mathrm{F})}$ & 1360 & 560 & 520 & 0.1778 & \\
\hline $2-200 “$ & 840 & 560 & 460 & 0.1412 & 39.26 \\
\hline $3-400 “$ & 740 & 560 & 450 & 0.0764 & 57.00 \\
\hline $4-600$ “ & 780 & 560 & 445 & 0.0681 & 61.68 \\
\hline $5-800 “$ & 520 & 560 & 405 & 0.0354 & 80.04 \\
\hline
\end{tabular}

However, the corrosion data of C-steel, nickel and zinc which were calculated from their polarization curves are given in Tables 2-4, respectively. Several 
remarks could be recognized on reading the data of theses tables. The corrosion potential is always shifted toward less active values as the added concentration of ficus extract is increased. The extent of such potential shift depends on the type of metal and the nature of corrosive solution. On the other hand, the corrosion current decreases as the added extract concentration is increased. The calculated inhibition efficiencies are comparable to those obtained by weight loss experiments. Moreover, the addition of ficus extract changes slightly both the anodic and cathodic Tafel constants. However, in few cases the Tafel constants are remarkdly changed. This result indicates that ficus extract acts as mixed corrosion inhibitor. It could be also concluded that the presence of ficus extract does not change the corrosion mechanism in most tested cases.

Table 3. Electrochemical parameters of corrosion of nickel in different media.

\begin{tabular}{|c|c|c|c|c|c|}
\hline Medium & $\begin{array}{c}\beta_{\mathbf{a}} \\
\mathrm{mV} / \text { decade }\end{array}$ & $\begin{array}{c}-\beta_{\mathrm{c}} \\
\mathrm{mV} / \mathrm{dec} \text { ede } \\
\end{array}$ & $\begin{array}{c}-\mathbf{E}_{\text {corr }} \\
\mathrm{mV}\end{array}$ & $\begin{array}{c}\mathbf{i}_{\text {corr }} \\
\mathrm{mA} / \mathrm{cm}^{2}\end{array}$ & IE\% \\
\hline 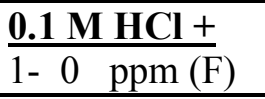 & 430 & 490 & 230 & 0.7356 & \\
\hline $2-200$ "6 & 220 & 420 & 205 & 0.3415 & 53.58 \\
\hline $3-400 " 6$ & 200 & 455 & 180 & 0.2511 & 65.85 \\
\hline $4-600$ " & 190 & 465 & 190 & 0.2326 & 68.377 \\
\hline $5-800 “$ & 180 & 450 & 179 & 0.1525 & 79.26 \\
\hline$\frac{3.5 \% \mathrm{NaCl}+}{1-0 \mathrm{ppm}(\mathrm{F})}$ & 210 & 490 & 190 & 0.0316 & \\
\hline $2-200$ “ & 180 & 450 & 165 & 0.0141 & 55.33 \\
\hline $3-400 "$ & 175 & 420 & 167 & $8.57 \times 10^{-3}$ & 72.87 \\
\hline $4-600 " 6$ & 125 & 415 & 63 & $5.62 \times 10^{-3}$ & 82.21 \\
\hline $5-800 " 6$ & 140 & 410 & 55 & $4.13 \times 10^{-3}$ & 86.90 \\
\hline 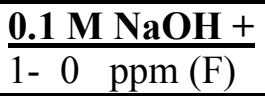 & 640 & 640 & 495 & 0.2818 & \\
\hline $2-200$ “ & 610 & 540 & 210 & 0.0316 & 88.78 \\
\hline $3-400$ " & 650 & 535 & 222 & 0.0271 & 90.37 \\
\hline $4-600$ “ & 550 & 500 & 200 & 0.0141 & 94.99 \\
\hline $5-800^{\prime \prime}$ & 650 & 500 & 180 & 0.0121 & 95.70 \\
\hline
\end{tabular}

Fig. 2 represents the potentiodynamic curves of $\mathrm{C}$-steel, nickel and zinc in $0.6 \mathrm{M}$ $\mathrm{NaCl}$ solutions devoid of and containing different concentrations of ficus extract. The curves were traced at voltage scanning rate of $1.0 \mathrm{mV} \cdot \mathrm{sec}^{-1}$. Inspection of Fig. 2 reveals that the current still almost constant at low potential values up to a specific value at which the current increases sharply. The potential value corresponding to this sharp increase in current was taken as pitting potential. Further inspection of Fig. 2 reveals that the addition of ficus extract shifts the pitting potential, for the three metals, to more noble direction. The extent of this potential shift depends on type of metal as following: $\mathrm{Ni}>\mathrm{C}$-steel $>\mathrm{Zn}$. This result indicates that the presence of ficus extract in a medium containing pitting 
agent (e.g., $\mathrm{Cl}^{-}$), inhibits the pitting corrosion. The visual examination of metal surface reveals that the number of pits is markedly reduced as the concentration of ficus extract was increased.

Table 4. Electrochemical parameters of zinc corrosion in different media.

\begin{tabular}{|c|c|c|c|c|c|}
\hline Medium & $\begin{array}{c}\boldsymbol{\beta}_{\mathbf{a}} \\
\mathrm{mV} / \text { decade }\end{array}$ & $\begin{array}{c}-\boldsymbol{\beta}_{\mathbf{c}} \\
\mathrm{mV} / \text { decade }\end{array}$ & $\begin{array}{c}-\mathbf{E}_{\mathbf{c o r r}} \\
\mathrm{mV}\end{array}$ & $\begin{array}{c}\mathbf{i} \text { corr } \\
\mathrm{mA} / \mathrm{cm}^{2}\end{array}$ & IE\% \\
\hline \multicolumn{6}{|l|}{$\frac{0.1 \mathrm{M} \mathbf{H C l}+}{1-0 \mathrm{ppm}(\mathrm{F})}$} \\
\hline $2-200 “$ & 260 & 100 & 970 & 3.88 & 29.20 \\
\hline \multirow{3}{*}{$\begin{array}{l}3-400 \\
4-600 \\
5-800\end{array}$} & 300 & 100 & 945 & 3.74 & 31.87 \\
\hline & 230 & 80 & 955 & 2.97 & 45.88 \\
\hline & 260 & 70 & 940 & 2.64 & 51.77 \\
\hline \multirow{5}{*}{$\begin{array}{l}3.5 \% \\
1-0 \quad \mathrm{NaCl}+ \\
2-200 \text { “ } \\
3-400 \text { “ } \\
4-600 \text { “ } \\
5-800 \text { “ } \\
\end{array}$} & 65.0 & 290.0 & 1053 & 0.1711 & - \\
\hline & 57.5 & 272.0 & 1058 & 0.0891 & 47.92 \\
\hline & 67.5 & 265.0 & 1057 & 0.0681 & 60.19 \\
\hline & 50.0 & 265.0 & 1050 & 0.0541 & 68.37 \\
\hline & 52.5 & 262.5 & 1040 & 0.0368 & 78.44 \\
\hline \multirow{5}{*}{$\begin{array}{l}\mathbf{0 . 1} \mathbf{M ~ N a O H}+ \\
1-0 \text { ppm (F) } \\
2-200 \text { “ } \\
3-400 \text { “ } \\
4-600 \text { “، } \\
5-800 \text { “ }\end{array}$} & 950 & 500 & 1330 & 1.8475 & - \\
\hline & 850 & 475 & 1065 & 0.3162 & 82.88 \\
\hline & 800 & 450 & 1047 & 0.2238 & 87.88 \\
\hline & 950 & 375 & 1086 & 0.1920 & 89.60 \\
\hline & 850 & 400 & 1107 & 0.1412 & 92.35 \\
\hline
\end{tabular}

\section{Discussion}

The above results indicated that ficus extract acts as fairly good inhibitor for corrosion of the three tested metals. The polarization experiments showed that the extract acts as mixed corrosion inhibitor. Moreover, the presence of the extract did not change the corrosion mechanism. Therefore, it could be concluded that the extract establishes its inhibitive action via adsorption of its component molecules on the metal surface. This adsorption process makes a barrier between the metal and corrosive media leading to inhibition of corrosion. Accordingly, the inhibition efficiency increases as the metal surface area covered by the adsorbed molecules is increased. The later is increased by increasing the extract concentration. This argument is in agreement with the experimental results. For determination of the mode of adsorption the relation between extract concentration and the fraction of metal surface covered by the adsorbed molecules $(\theta)$ must be obtained. Because the direct relation between $(\theta)$ and the inhibition efficiency, $(\theta)$ was calculated using the data of Tables 2-4 as $\theta=$ $\mathrm{IE} / 100$. 


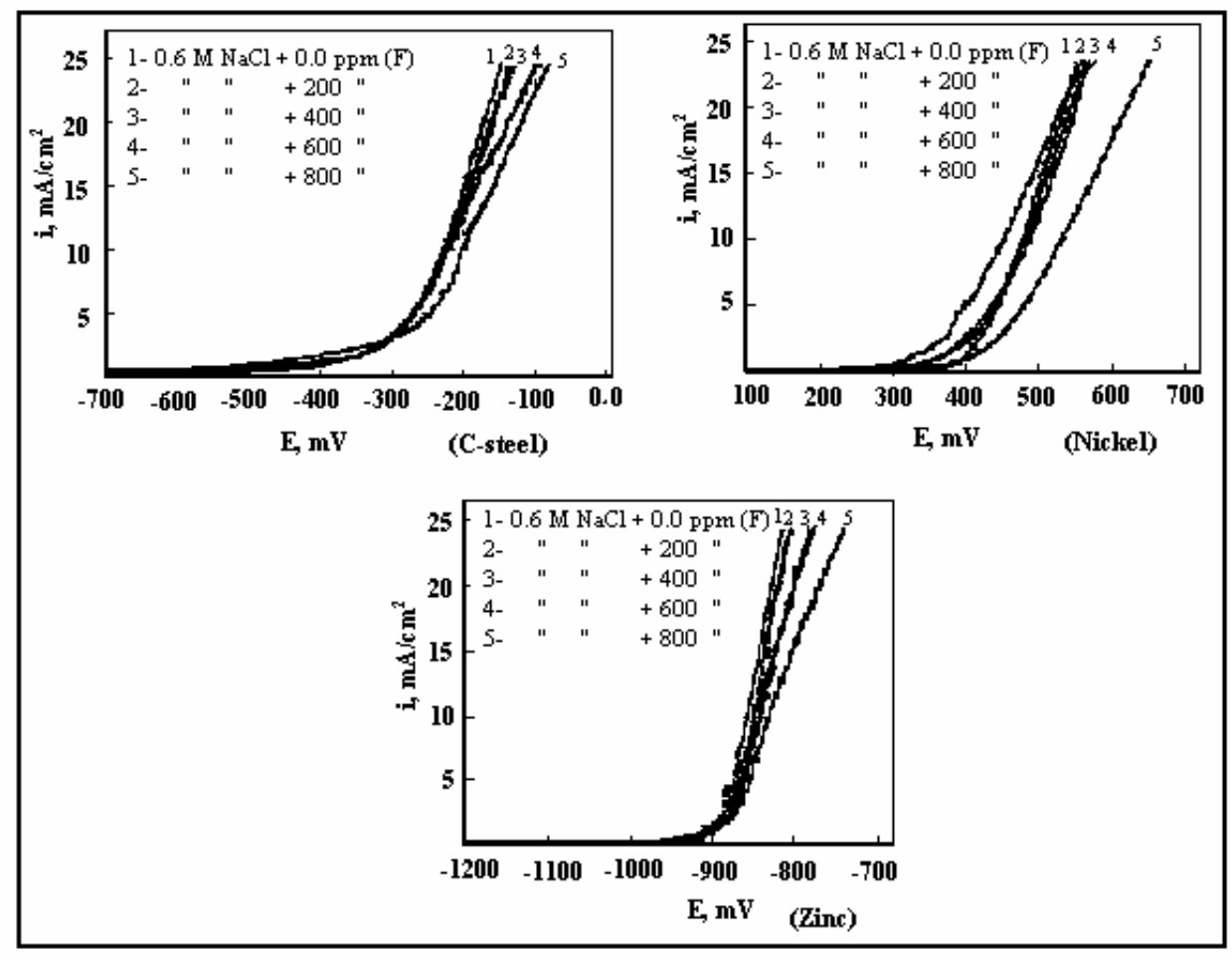

Figure 2. Potentiodynamic polarization of the three electrodes in free and inhibited chloride solutions.

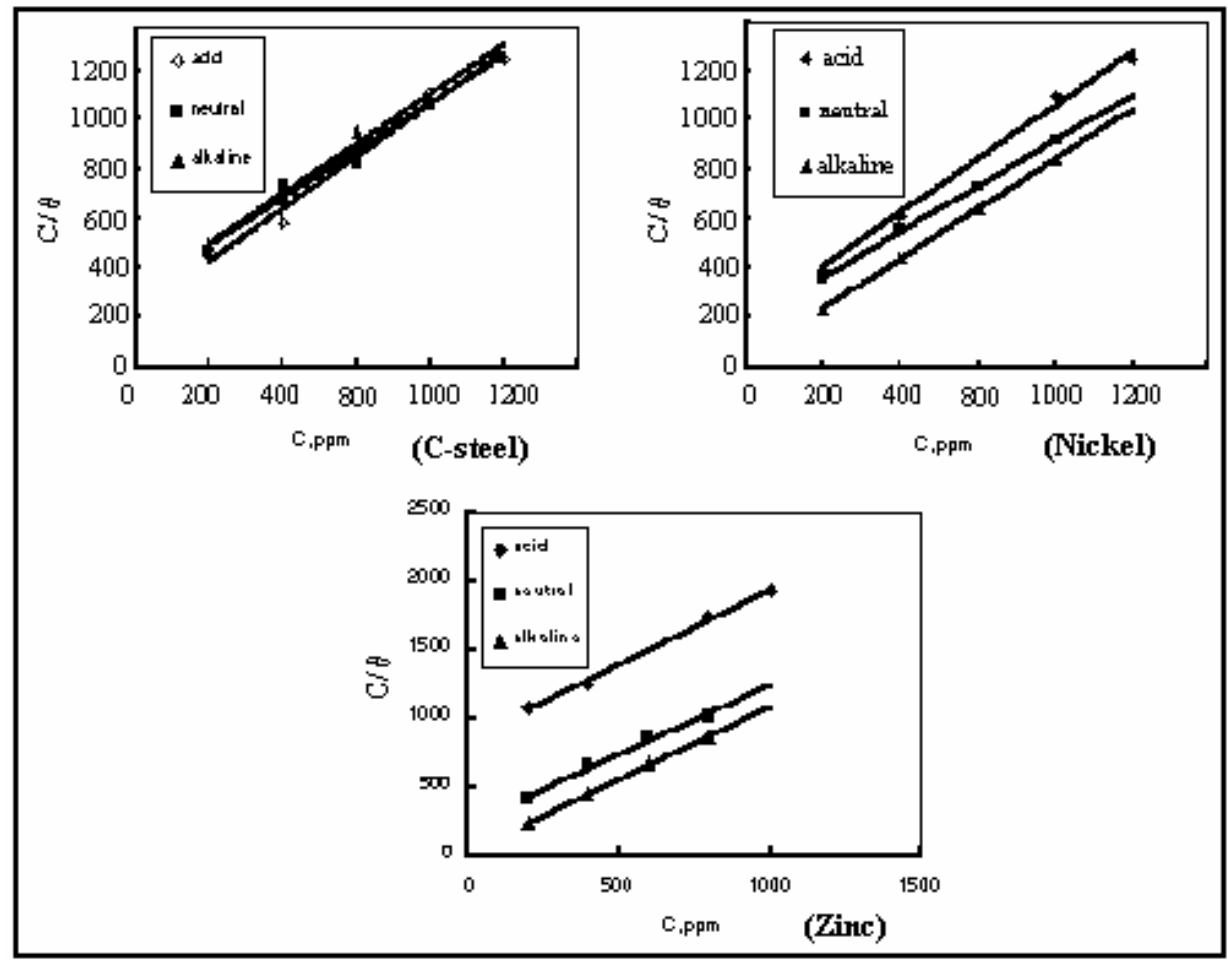

Figure 3. Adsorption isotherms for C-steel, nickel and zinc. 
Fig. 3 represents the relationships between the concentration of ficus extract $\mathrm{C}$ and $\mathrm{C} / \theta$ for $\mathrm{C}$-steel, nickel and zinc, respectively. Inspection of the figures reveals that every relations give a straight line with almost unit slope. These results indicate that the adsorption of ficus extract molecules on the tested metals in different media follows Langmuir adsorption isotherm. This isotherm postulates that there is no interaction force between the adsorbed molecules, and the free energy of adsorption $\Delta G_{a d}^{o}$ does not depend on the surface coverage $\theta$.

Langmuir adsorption isotherm could be described as following:

$$
\frac{C}{\theta}=\frac{1}{K}+C
$$

where $\mathrm{K}$ is the adsorption constant and

$$
\ln \mathrm{K}=\ln \frac{1}{55.5}-\frac{\Delta G_{a d}^{o}}{R T}
$$

The standard free energies for adsorption were calculated using eq. (2), where one molecule of water is replaced by one molecule of inhibitor [17]. The numerical value (1/55.5) in eq. (2) stands for the molarity of water. The values of $\Delta G_{a d}^{o}$ for the different studied systems are given in Table 5. Inspection of Table 5 reveals that the values of $\Delta G_{a d}^{o}$ are negative for all systems, suggesting that the adsorption processes are spontaneous. The affinity of adsorption is higher in acidic solution for nickel and zinc, while it is higher in alkaline solution in the case of C-steel.

Table 5. The values of $\Delta G_{a d}^{o}\left(\mathrm{~kJ}_{\mathrm{mol}} \mathrm{m}^{-1} \cdot \mathrm{K}^{-1}\right)$ of ficus extract on different metals in different media.

\begin{tabular}{|c|c|c|c|}
\hline Ficus & C-steel & Nickel & Zinc \\
\hline Acid & -23.27 & -22.78 & -26.64 \\
\hline Neutral & -23.12 & -22.74 & -23.51 \\
\hline Alkali & -24.15 & -18.24 & -18.79 \\
\hline
\end{tabular}

The aqueous extract of the leaves of Ficus nitida Thumb (Fikus, Lisan-el-asforr) is used in the present study. Inspection of the obtained results reveals that the extract acts as inhibitor for corrosion of C-steel, nickel and zinc in the acidic, neutral and alkaline media. It was reported that the leaves of Ficus nitida contain friedelin, epifriedelanol, nitidol (a triterpene, $\mathrm{C}_{10} \mathrm{H}_{50} \mathrm{O}$ ) and a mixture of two sterols [18,19] (Fig. 4). Inspection of Fig. 4 reveals that the compounds contained in the leaf extract of ficus are poly aromatic compounds with attached oxygen atom in one direction and, in sterols, a hydrocarbon chain at the opposite direction. The presence of attached oxygen atom may be responsible for the adsorption of such compounds on the metal surface. Therefore, the compounds are adsorbed on the metal surface through the lone pair of electrons present on the oxygen atom while the rest of the molecule is oriented toward the solution. 
The aromatic cycles as well as the hydrocarbon chains repel the aqueous solution out of the electrode surface leading to inhibition of the attack of the aggressive solution on the metal surface.
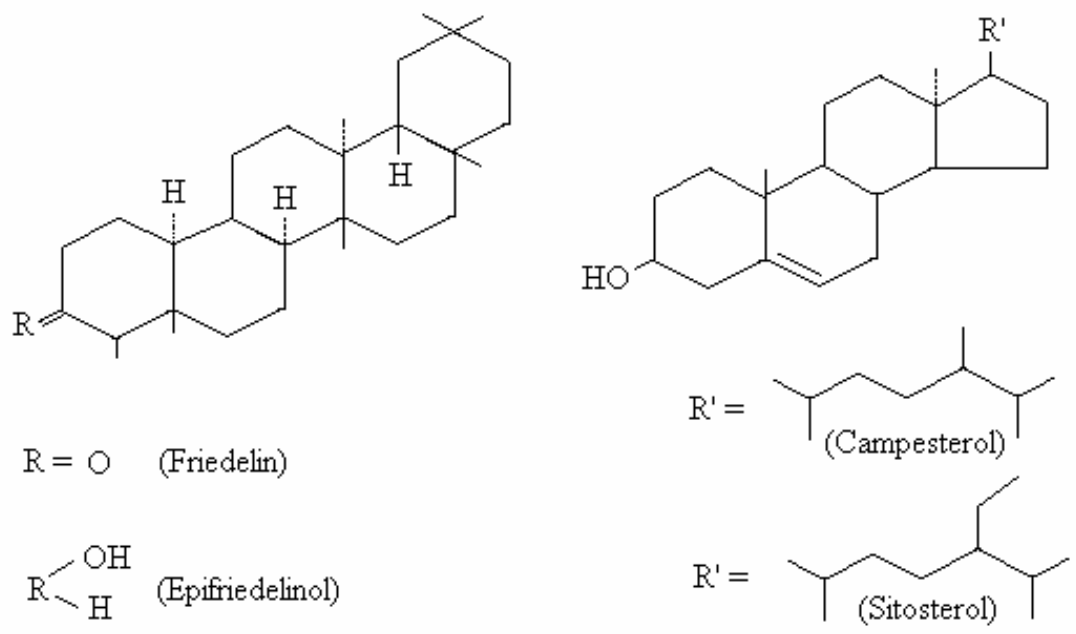

Figure 4. Chemical structures of some compounds contained in ficus extract.

\section{Conclusions}

1- The extract of ficus leaves acts as good corrosion inhibitor for C-steel, nickel and zinc in the acidic, neutral and alkaline media.

2- The presence of the extract in chloride solution decreases the susceptibility of the tested metals to pitting corrosion.

3- The inhibitive action of the extract is due to the adsorption of its molecules on the metal surface.

4- The adsorption of extract molecules on the metal surface is a spontaneous process which follows Langmuir adsorption isotherm.

\section{References}

1. Ling-Guang Qiu, An-Jian Xie and Yu-Hua Shen, Corros. Sci. 47 (2005) 273.

2. K. Sapre, S. Seal, P. Jepson, H.B. Wang, Z. Rahman and T. Smith, Corros. Sci. 45 (2003) 59.

3. F. Zucchi, G. Trabanelli, C. Monticelli and V. Grassi, Corros. Sci. 42 (2000) 505.

4. Rong Guo, Tianqing Liu and Xun Wei, Colloids Surf. 209 (2002) 37.

5. M.R. Laamari, A. Derja, J. Benzakour and M. Berraho, J. Electroanal. Chem. 569 (2004) 1.

6. E.E. Foad El-Sherbini, S.M. Abdel Wahaab and M. Deyab, Mater. Chem. Phys. 89 (2005) 183.

7. M.A. Pech-Canul and P. Bartolo-Pérez, Surf. Coat. Tech. 184 (2004) 133.

8. M. Abdallah, Corros. Sci. 45 (2003) 2705. 
9. A.Y. El-Etre, M. Abdallah and Z.E. El-Tantawy, Corros. Sci. 47 (2005) 385.

10. A.Y. El-Etre and M. Abdallah, Corros. Sci. 42 (2000) 731.

11. A.Y. El-Etre, Corros. Sci. 45 (2003) 2485.

12. A.Y. El-Etre, Corros. Sci. 40 (1998) 1845.

13. R.M. Saleh, A.A. Ismail and A.A. El-Hosary, Br. Corros. J. 17 (1982) 131.

14. S.A. Verma and G.N. Mehta, Bull. Electrochem. 15 (1999) 67.

15. S. Martinez and I. Stagljar, J. Molecular Structure 640 (2003) 167.

16. M.A. Quraishi, I.H. Farooqi and P.A. Saini, Corrosion 55 (1999) 493.

17. I.O'M. Bockris and D.A. Swinkls, J. Electrochem. Soc. 111 (1964) 736.

18. M.H.A. Elgamal, B.A.H. El-Tawil and M.B.E. Fayez, Naturwissenschaften 62 (1975) 486.

19. M. Behari, K.U. Rani, T. Matsumoto and N. Shimizu, Curr. Agric. 8 (1984) 73. 